\title{
"Scientific connectivity of European regions: towards a typology of cooperative schemes "
}

\author{
$\underline{\text { Auteurs }}$ \\ M. Benaim, J. A. Héraud, V. Mérindol, J. P. Villette
}

Document de Travail $n^{\circ} 2014-13$

Juillet 2014

Faculté des sciences économiques et de gestion Pôle européen de gestion et d'économie (PEGE) 61 avenue de la Forêt Noire F-67085 Strasbourg Cedex

Secrétariat du BETA Géraldine Del Fabbro Tél. : (33) 0368852069 Fax : (33) 0368852070 g.delfabbro @unistra.fr www.beta-umr7522.fr 


\section{Scientific connectivity of European regions: towards a typology of cooperative schemes}

Benaim M., Héraud J.A., Mérindol, V., Villette J.P.

BENAIM Mickael

Mail: mickael.benaim@mbs.ac.uk

Manchester Institute of Innovation Research, MIOIR, University of Manchester

Harold Hankins Building, Booth Street West - Manchester M15 6PB United-Kingdom

Bureau d'Économie Théorique et Appliquée, BETA-CNRS, UMR 7522, Université de Strasbourg

61 avenue de la Forêt Noire F-67085 Strasbourg Cedex

HÉRAUD Jean-Alain

Mail: heraud@unistra.fr

Bureau d'économie théorique appliqué, BETA-CNRS, UMR 7522, Université de Strasbourg 61 avenue de la Forêt Noire F-67085 Strasbourg Cedex

MERINDOL Valérie

Mail: valerie@merindol.net

Research lab, ESG Management School

25 rue St Ambroise

75011 Paris

VILLETTE Jean-Paul

Mail: villette@unistra.fr

Bureau d'économie théorique appliqué, BETA-CNRS, UMR 7522, Université de Strasbourg 61 avenue de la Forêt Noire F-67085 Strasbourg Cedex 


\title{
Scientific connectivity of European regions: towards a typology of cooperative schemes
}

\begin{abstract}
The diversity of European regions in terms of $R \& D$ and of absorptive capacities has been extensively investigated but without taking into account all dimensions of the regional innovation systems. Even though the variety of connections is a source of constraints and opportunities for the development of territories, few analytical contributions have been devoted so far to this subject and to the implications for regional public policies. This article aims at contributing to the analysis of regional research and innovation systems. It focuses on the different types of scientific connectivity present at local to global levels, and proposes a typology of European regions based on co-publication statistics. It links this characterization of European regions with regional policy issues and discusses the relevance of these measures. The typology of scientific connectivity produces new maps of European regions, and challenges the classical R\&D point of view about regional systems.
\end{abstract}

JEL: O18, O31, R11, R58

\section{Key words}

European regions, global-local connectivity, regional public policy, absorptive capacity, scientific activities 


\section{Scientific connectivity of European regions: towards a typology of cooperative schemes}

\section{INTRODUCTION}

The diversity of European regions in terms of R\&D and of absorptive capacities (OUGHTON et al., 2002; PINTO, 2009) has been extensively investigated but without taking into account all the dimensions of the regional innovation systems (COOKE, 2005), in particular the scientific networks. This diversity has increased with the emergence of a new form of multilevel governance of research and innovation policies in Europe, due to the globalization of scientific, technological and industrial activities. Even though the variety of (local and international) connections is a source of constraints and opportunities for the development of territories, few analytical contributions have been devoted so far to the subject and to the subsequent implications on public policies (BENNEWORTH, 2010). This article aims at contributing to the analysis of Regional Innovation Systems (RIS), focusing on the different types of connectivity (BENNEWORTH and DASSEN, 2011) involved from the local to the global levels.

This article addresses two main issues: (i) the analysis of scientific connectivity at regional level as a major aspect of RIS and innovation policies, (ii) the production of bibliometric indicators in order to characterize European regions. Section 1 presents the issue of regional scientific connectivity. It focuses of the main academic results related to the regional connectivity in general and then it points out the specific stake associated wit the the scientific regional connectivity. Section 2 proposes a typology of European regions based on copublication statistics. Section 3 links this characterization of European regions with policy issues and discusses the relevance of the measures of scientific connectivity.

\section{REGIONAL SCIENTIFIC CONNECTIVITY}


This section focuses on the theoretical background and the policy context for the study of scientific connectivity at regional level. The first sub-section analyses the systemic issue of regional development, stressing the role of internal and external relationships. The sub-section 2.1 is based on an analysis of the connectivity in the global context of the regional innovation system (RIS). The sub-section 2.2 points out a specific subsystem inside the RIS : the scientific subsystem and analyses the specificity of scientific connectivity.

\subsection{The stakes of regional connectivity}

The concept of RIS assumes a systemic coherence of the actors, such as academic institutions, national agencies, industrial firms, knowledge-based services, local governments, etc., that are present and active on the territory and leading to potential localized comparative advantages (COOKE, 2001; ASHEIM et al., 2005; ASHEIM, 2006). The RIS approach underwent a considerable expansion in the 90s, resulting from several simultaneous phenomena, mainly (i) the rising interest of researchers for the understanding of localized dynamic interactions and their impact on innovation (COOKE, 2001; BRUIJN et al., 2005) and (ii) the efforts of policymakers to define a relevant conceptual framework for local intervention, following the paradigm of the "knowledge-based economy" (OUGHTON et al., 2002). Nevertheless, the concepts associated to RIS are not fully clear and justified (HÉRAUD, 2003, DOLOREUX and BITARD, 2005; TÖDTLING et al., 2005; UYARRA, 2010). Among the criticisms, the lack of consideration devoted to the variety of connections the actors develop within the territory and with the exterior should be stressed (BARTHELT et al., 2004; MALECKI and OINAS, 1999).

The various formal and informal relations of actors are definitely a central characteristic of regional innovation systems (COOKE, 2005; BENNEWORTH, 2010), but one of the main limitations of many RIS approaches is to consider the territory more or less as a closed system. At least implicitly, such a vision is that of the policymakers in charge of the territories and it is difficult, in practice, to convince them to consider the issue of local development in another perspective, where many functionalities are not optimally located and piloted within the territory (UYARRA and FLANAGAN, 2013). For them, local specializations and collective strategies are mainly thought of as resulting from internal dynamic processes (COOKE, 2005; BENNEWORTH and DASSEN, 2011), over-evaluating the endogenous schemes of development. In fact, "knowledge regions" derive their ability to innovate and to develop from a complex and specific combination of endogenous and exogenous factors 
(COOKE, 2005). Absorptive capabilities play an important role in these processes. Analysing local and global connectivity is a way to approach such a complex reality and to deal with the issue of local governance in a more realistic way, looking at all the various forms they can have (LEYDESDORFF et al., 1998; LEYDESDORFF, 2003; MORENO and MIGUÉLEZ, 2012). Taking into account local and global connectivity, two major stakes are rationally to be considered:

- The first is the issue of the internal coherence of the system at hand, and of all the subsystems involved. The dynamics of innovation strongly rely on such a coherence (LUNDVALL et al., 2002). However, it is rarely considered at regional level (ANOVA et al., 2001). It will depend on many factors to be investigated: local history and institutions, types of relations between local/regional authorities, and relations to upper governance structures (central State, EU). For sure, it is not granted that any "region" has a fully fledged innovation system.

- The second issue is to consider the actors' links with the external world (BENNEWORTH et al., 2010) and their impact on local development strategies (MARKUSEN, 1994). Such relationships have been studied, typically, at the level of multinational firms (NIOSI and ZHEGU, 2005; MALTES, 2006; BAIER, 2011) where division of labour and other internal strategies impact the fate of territories.

Local and global connections are possible sources of advantages, risks and tensions for local development (BENNEWORTH et al., 2010). The variety of connections can reduce lock-in effects (BENNEWORTH and HOSPERS, 2007), create new forms of diversity resulting not only from internal sources of knowledge but also from the capability of local actors to mobilize knowledge from the outside. The COHEN and LEVINTHAL's (1990) theory of absorptive capacities should be generalized to the larger domain of regional innovation systems: the translation/reinterpretation of external knowledge is a potential source of innovative activities (HÉRAUD, 2011). Global-local connectivity is possibly a source of tensions as well as a source of innovation. In some cases, actors are under the pressure of external dynamics (of sectors, markets, alliances...) that counteract local development. Whatever the nature and effect of the external influences, local-global connectivity influences local governance and the relationships within the triple helix model involving regional authorities, firms and academic institutions (COOKE, 2004; ETZKOWITZ and LEYDESDORFF, 1997; LEYDESDORFF et al., 1998). 


\subsection{From connectivity in general to scientific connectivity}

Contributions on regional connectivity mostly focus on firms (MARKUSEN, 1994; UYARRA, 2010) or on science-industry relationships (KRATLE et al., 2009). Scientific connectivity is much less studied as a basic component of innovation systems. Scientific connectivity reflects the collaborative attitude of researchers in the creation of new knowledge, their networks, the types of communities (AMIN and COHENDET, 2004) they belong to, and many other characteristics that are to a certain extent typical of the territory. Meanwhile, scientific activities follow their own path. They represent a complex subsystem linked to local, national and international networks (TÖDTLING et al., 2005).

This article aims at stressing the importance of scientific activities for regional development, because even the basic research activities contribute - endogenously as well as exogenously to such a development through various ways: human capital building, attractiveness linked to the image, etc (TÖDTLING et al., 2005).

Scientific activities are part of the RIS and contribute to the innovation process. Universities and public research organisations are nowadays appreciated as key actors for the stimulation of local-global connectivity (BENNEWORTH et al., 2009). They facilitate the openness of the regional systems and help resist lock-in phenomena (BENNEWORTH and HOSPERS, 2007). Image and reputation from scientific achievements are sometimes highly considered in certain regions (CRESPY et al., 2007). Nevertheless, networks of scientific production are generally not addressed. A novel vision of innovative processes has recently been developed around the so-called open innovation model, but, again, scientific networks are not considered in their geographical dimension, because science generally appears as a very globalized activity. The structuring of scientific networks is viewed as a self-organized process (GEORGHIOU, 1998; WAGNER and LEYDESDORFF, 2005) with few possibilities of intervention for policymakers at regional level. Furthermore, localized spinoffs are generally not expected.

Nevertheless, this paper advocates the idea that regional networks of knowledge creation play an important role. Scientific activity has always been - and probably is increasingly - relying on collaborations between researchers, and various forms of proximity are central to the success of collaboration: geographical vicinity as well as other dimensions which are often positively correlated like language and culture. Scientific collaborations between academics deal very often with the creation of new generic and fundamental knowledge. The results of 
the collaboration materialize with scientific publications in respect with the rules and governance of the science by Scientifics communities organized at international level.

As for the intensification of collaborative behaviour, the main explanation to be found in the literature is researchers' specialization combined with the increasing complexity of science (ADAMS et al., 2005; TIJSSEN et al., 2007). Along with the analysis of international collaboration, the literature focuses on the subject of proximity in the construction of collaborative research networks. International collaborations have increased during the last three decades (LUUKKONEN et al., 1992 \&1993; GEORGHIOU, 1998; WAGNER and LEYDESDORFF, 2005), and this result could lead to the conclusion that proximity does not matter so much. Motivations for collaboration are multifaceted, as shown in GEORGHIOU (1998), BEAVER (2001), WAGNER (2005), and WAGNER and LEYDESDORFF (2005): historical links like colonial ones; finding financial opportunities; necessity to share costly infrastructures; finding complementarities. Another motivation is the reputation factor. Some authors suggest that the main reason to collaborate internationally refers to scientific excellence. It is true that international publications are more quoted than the others (FRENKEN et al., 2009). Motivations vary among disciplines (WAGNER, 2005) but internationalization is a general rule.

Some contributions bring more detail on the collaboration behaviour (TORRE, 2008), and can help us put important nuances into the general picture. GLANZER (2001) observes that the intensity of international collaboration seems to diminish with the "size" of the actor (measured by the number and quality of publications). WAGNER et al. (2001) found a decreasing necessity for large scientific actors to go abroad for finding complementary competences. These results suggest also that the main source of scientific creativity increasingly relies on integrated international networks (PERSSON et al., 2004). At least for regions at low and intermediate levels of scientific excellence, internationalization of these activities is a crucial strategic factor.

On the other hand, proximities still facilitate the creation and functioning of scientific networks (ZUCKER et al., 1998; ZITT et al., 2000; OKUBO et al., 2004; FRENKEN et al., 2009; HOEKMAN et al., 2010). Face to face relations play an important role, at least at some stages of the collaboration. Geographical proximity is a key factor for launching a research team. Science parks and innovation clusters try to play on this property for initiating networks (BEAUDRY et al., 2000). There is still also a noticeable positive bias to scientific 
collaborations within national spaces, a phenomenon that can easily be explained by cultural as well as organizational/institutional factors. Finally, one can conclude that the complex system of scientific collaboration is the result of many dynamics and tensions between various sorts of local and global connectivity.

The next point to examine is the policy implications. BENNEWORTH et al. (2011) argue that policymakers should support such connectivity for the sake of local development. Some examples can be given in the case of French and German regions showing the variety of the perceptions of science at regional level.

- Some regions rely on science for reputation and for its own value. In France, it is typically the case of Rhône-Alpes. It is the most prominent RIS outside the capital region Ile-deFrance, and it has a strong reputation in technological achievements. Its scientific production is far from negligible (13\% of French publications), but the local policymakers want to reinforce excellence in science (CONSEIL RÉGIONAL DE RHÔNE-ALPES, 2010). In a quite different situation, the German Eastern Länder also consider science as a priority for cultural reasons.

- Other regions envisage scientific activities as opportunities to improve absorptive capacities. Having in mind the necessity to escape lock-in situations - in traditional activities - internal links with local scientific researchers as well as establishing contacts with global science are considered as positive factors. It is typically the case for Aquitaine that exhibits the highest relative expenditure in French regional budget $(10 \%)$ devoted to scientific programs and technology transfer operations (LA RECHERCHE, 2011). The case of Saarland in Germany could be considered in this same category - here in a more industrial context.

- Facing a problem of critical mass, smaller regions rely on external connectivity in order to be able to participate in large programs (typically European consortia). It is the case of Basse-Normandie in France, as we could observe in an enquiry carried out in 2011.

The following section is devoted to a systematic analysis of regional characteristics in terms of science connectivity. Using co-publication statistics as indicators, we intend to typify regions. This will cast light on the variety of European territories as well as on the strategies of their policymakers. 


\section{TYPOLOGY OF REGIONAL SCIENCE CONNECTIVITY IN EUROPE}

\subsection{Methodology}

\subsubsection{Presentation of the data}

The data used were constructed by the Observatoire des Sciences et des Techniques (OST) and based on an original data set of Web of Science (WoS). Scientific co-authorship statistics were regionalized at the NUTS- $2^{1}$ level according to the institutional address of the authors listed in about 255435 publications in 2009. The data was regionalized for 243 Europeans regions $^{2}$.

This typology is based on eight different indicators that cover all available disciplines in hard science and reflect the different geographical levels of collaboration that fall within different institutional contexts:

- Intra-institutional co-publications: scientific publications produced by one or several scientists from the same institution. It shows a lack of scientific connection or a narrow connectivity.

- Intra-regional co-publications: produced by at least two researchers from institutions located in the same region. Such a collaborative behavior is possibly influenced by regional policies promoting territorial connectivity.

- Co-publications among regions from the same country (except the region itself). The country level is characterized by the existence of institutions and scientific policies that have a major influence on the governance of research and specialization (classical concept of national innovation system).

- European co-publications: co-authorship between one institution and another outside the national boundaries but located in Europe. The European territory is a specific and unique institutional context in which policy measures for $R \& D$ have been

\footnotetext{
${ }^{1}$ We considered the NUTS-2 level as the more relevant scale for our study covering all European regions. For some countries, the choice of the NUTS-3 level could make more sense regarding their scientific governance. But we privileged the uniformity of analysis and the potential benchmark with existing typologies (see Navarro and Gibaja 2009 for a review)

2 It has been not possible to regionalize the publications for Denmark, Luxembourg, Latvia, Estonia, Cyprus, Lithuania, Malta and Slovenia. We included those "special" Nuts-2 as illustrative individuals i.e. we projected them afterward on the statistical axes built on our 243 European regions
} 
implemented and mainly dedicated to the development of European cooperation (for the cohesion of the Union).

- International collaborations through two indicators: the co-publications between an European region and the USA, and the co-publications with China, Japan or other international (i.e. non-European and non-US) partners. As underlined by GEORGHIOU (1998), the international level of scientific cooperation is mostly driven by self-organization mechanisms.

Each indicator was regionalized and stabilized (smoothed over three years) to prevent unusual rebounds in the data set and to make the trend more obvious (see OST 2009 ${ }^{3}$ ). These indicators are percentage. So they neutralize the size of regions. The goal is to compare collaborative patterns and not absolute co-publications production.

Some others indicators have been used as additional data called illustrative variables. They were projected backward on the computed axes. The illustrative variables have been dichotomized into two categories: First category is related to the size and the economic activity of the regions: population in millions inhabitants, GDP (in millions SPA) and the percentage of intensive human capital (RHST in percentage of the region's inhabitants). The second category is linked with some of the main scientific specificities of the regions: the scientific size (number of the publications), the disciplinary specialisation (index of specialization) and the scientific visibility (impact factor). To test the influence of scientific visibility, the 2-year impact index computed « for all disciplines » and « by discipline » (ZITT et al., 2000) is used. This index gives a measure of the average citation rate (received in 2 years) of the regions' publications.

The next table presents the descriptive statistics available in our database.

Table 1 - Descriptive statistics at the regional level 2009

\begin{tabular}{|c|c|c|c|c|c|}
\hline & $\begin{array}{l}\text { Co-publications of the region i } \\
\text { (Fractional counting) }\end{array}$ & Min & Max & Mean & $\begin{array}{l}\text { Standard } \\
\text { Deviation }\end{array}$ \\
\hline \multirow[b]{3}{*}{ Active } & Intra-institution & 0.33 & 4083 & 418 & 519 \\
\hline & Intra-regional & 0 & 4062 & 250 & 411 \\
\hline & Other regions same country & 0 & 1329 & 151 & 173 \\
\hline
\end{tabular}

\footnotetext{
${ }^{3}$ Observatoire des Sciences et des techniques (2009): it is a standard bibliometric methodology: the annual amount of publications of the regions or countries are the average of the publications during 3 years. The regional publications of 2009 is the average of the publications of the years 2007, 2008 and 2009.
} 


\begin{tabular}{|c|c|c|c|c|c|c|}
\hline \multirow{2}{*}{ Data in 2009} & \multicolumn{2}{|c|}{ European } & 0 & 1089 & 99 & 133 \\
\hline & \multicolumn{2}{|c|}{ USA } & 0 & 443 & 35 & 53 \\
\hline $\begin{array}{c}\text { Available } \\
\text { for } 243 \text { Nuts-2 } \\
\text { in Europe }\end{array}$ & \multicolumn{2}{|c|}{ Other international } & 0 & 825 & 63 & 91 \\
\hline \multirow{13}{*}{ Illustrative $^{4}$} & \multicolumn{2}{|c|}{ Total Publications } & 0.63 & 1181.87 & 1015.90 & 1339.62 \\
\hline & \multicolumn{2}{|c|}{$\begin{array}{l}2 \text { years- Impact index (all } \\
\text { disciplines)* }\end{array}$} & 0.19 & 1.92 & 0.88 & 0.31 \\
\hline & \multicolumn{2}{|c|}{ GPD } & 948 & 488581 & 45400 & 50807 \\
\hline & \multicolumn{2}{|l|}{ RHST } & 6 & 3605 & 407.28 & 387.80 \\
\hline & \multicolumn{2}{|c|}{ Population } & 27456 & 11728240 & 1877864 & 1592654 \\
\hline & \multirow{8}{*}{ 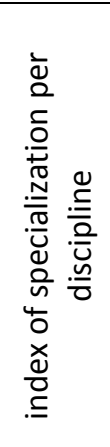 } & $\begin{array}{l}\text { Fundamental } \\
\text { Biology }\end{array}$ & 0.14 & 1.81 & 0.88 & 0.33 \\
\hline & & Medical science & 0.06 & 2.62 & 0.93 & 0.42 \\
\hline & & Applied Biology & 0 & 6.62 & 1.32 & 1.07 \\
\hline & & Chemistry & 0 & 3.01 & 1.01 & 0.53 \\
\hline & & Physics & 0 & 2.83 & 0.88 & 0.47 \\
\hline & & $\begin{array}{l}\text { Science of the } \\
\text { Universe }\end{array}$ & 0 & 6.98 & 1.13 & 0.85 \\
\hline & & Engineering & 0 & 4.52 & 1.12 & 0.65 \\
\hline & & Mathematics & 0 & 7.65 & 1.12 & 0.89 \\
\hline
\end{tabular}

Source: Bibliometric data collected and regionalized by OST; GDP and Population at the regional level from Eurostat database. Note that the illustrative individuals are not included in these statistics. * Only 230 Nuts-2 data available.

\subsubsection{Presentation of the classification}

The bibliometric data set was explored through a correspondence factorial analysis (CFA). This methodology is quite common in typologies' exercises (NAVARRO and GIBAJA, 2009). The first three axes represent about $92 \%$ of the standard deviation (Figure 1). Then, a hierarchical classification has been made in order to determine four main profiles of regions in terms of scientific connectivity.

Figure 1: interpretation of the first two axes

\footnotetext{
${ }^{4}$ Projected afterward on the axes (i.e. are not used for the computation of the CFA)
} 


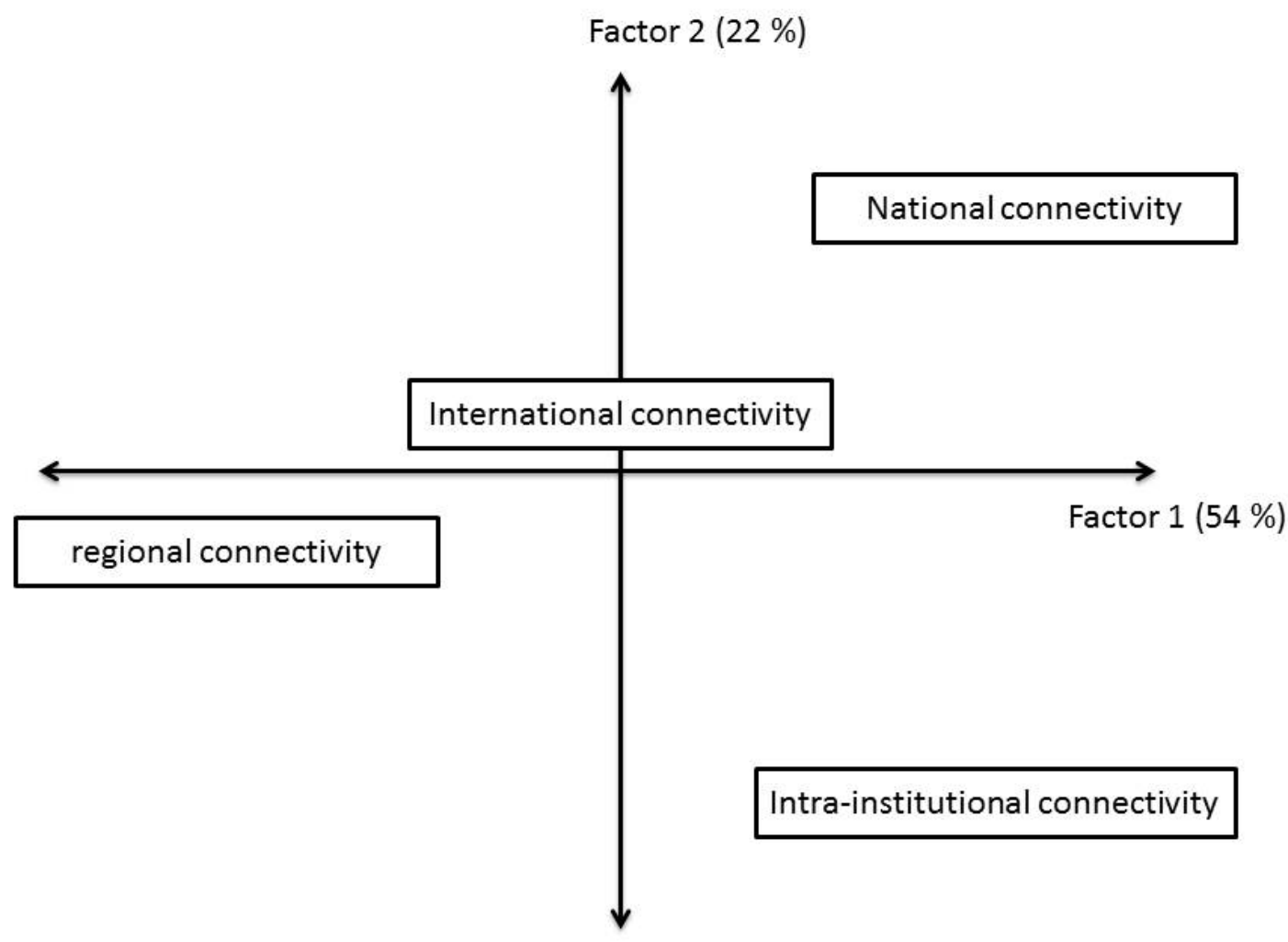

The aim of the CFA is to reduce the dimensions of our data set that contains all of the copublications in 2009 at the European Nuts-2 level (see DORÉ et al. 1996 for detailed methodology of the CFA in the same context).

The indicators of co-publications are overall additive. Basically the additivity property of our data set allows us to interpret the rows as profiles of collaboration. This method is equivalent to a conventional principal component analysis (PCA). But as DORÉ et al. (1996) noted the PCA is not applicable to categorical variables. "When dealing with counts (publications) rather than measurements, it is helpful to convert the data into Khi-2 frequency distribution" i.e. to prefer the CFA to a PCA method.

Table 2: Factor loadings of individual indicators

\begin{tabular}{|c|c|c|c|c|}
\hline Co-publications & Factor 1 & Factor 2 & Factor 3 & Factor 4 \\
\hline Intra-institution & 0.09 & -0.12 & -0.05 & 0.00 \\
\hline
\end{tabular}




\begin{tabular}{|c|c|c|c|c|}
\hline Intra-regional & -0.30 & 0.07 & -0.05 & -0.02 \\
\hline $\begin{array}{c}\text { Other regions same } \\
\text { country }\end{array}$ & 0.25 & 0.23 & -0.04 & 0.03 \\
\hline European & -0.10 & -0.04 & 0.21 & 0.13 \\
\hline USA & 0.02 & 0.01 & 0.13 & -0.05 \\
\hline Other international & 0.14 & 0.03 & 0.23 & -0.17 \\
\hline
\end{tabular}

Table 3: Eigenvalues on the first five axes

\begin{tabular}{|c|c|c|c|}
\hline & Eigenvalue & \% of variance & Cumulative \% \\
\hline 1 & 0.0365 & 54,73 & 54.73 \\
\hline 2 & 0.0147 & 22.12 & 76.85 \\
\hline 3 & 0.0100 & 14.99 & 91.84 \\
\hline 4 & 0,0038 & 5.47 & 97.31 \\
\hline 5 & 0,0018 & 2,69 & 100 \\
\hline
\end{tabular}

The eigenvalues table shows an unusual fall to zero starting form the third factor. According to this rule ("elbow criteria" ${ }^{5}$ ), we can retain two or three factors in the analysis of the copublications. The first two axes explains $76,85 \%$ of the variance (see Table 3 ).

\subsection{The results: a typology of regional scientific connectivity}

Regions with similar structures of co-publications (connectivity profile) are allocated to the following four clusters (cf. Figure 2). The clusters present a maximum of similarities "within" and of differences "between". They are determined following a hierarchical classification method described in Appendix A.

Figure 2. The four clusters on the factor analysis plan

\footnotetext{
${ }^{5}$ In conventional Principal Component Analysis, the Kaiser's (1960) or Cattell's (1966) criteria can be used to select the factors according to the eigenvalues.
} 


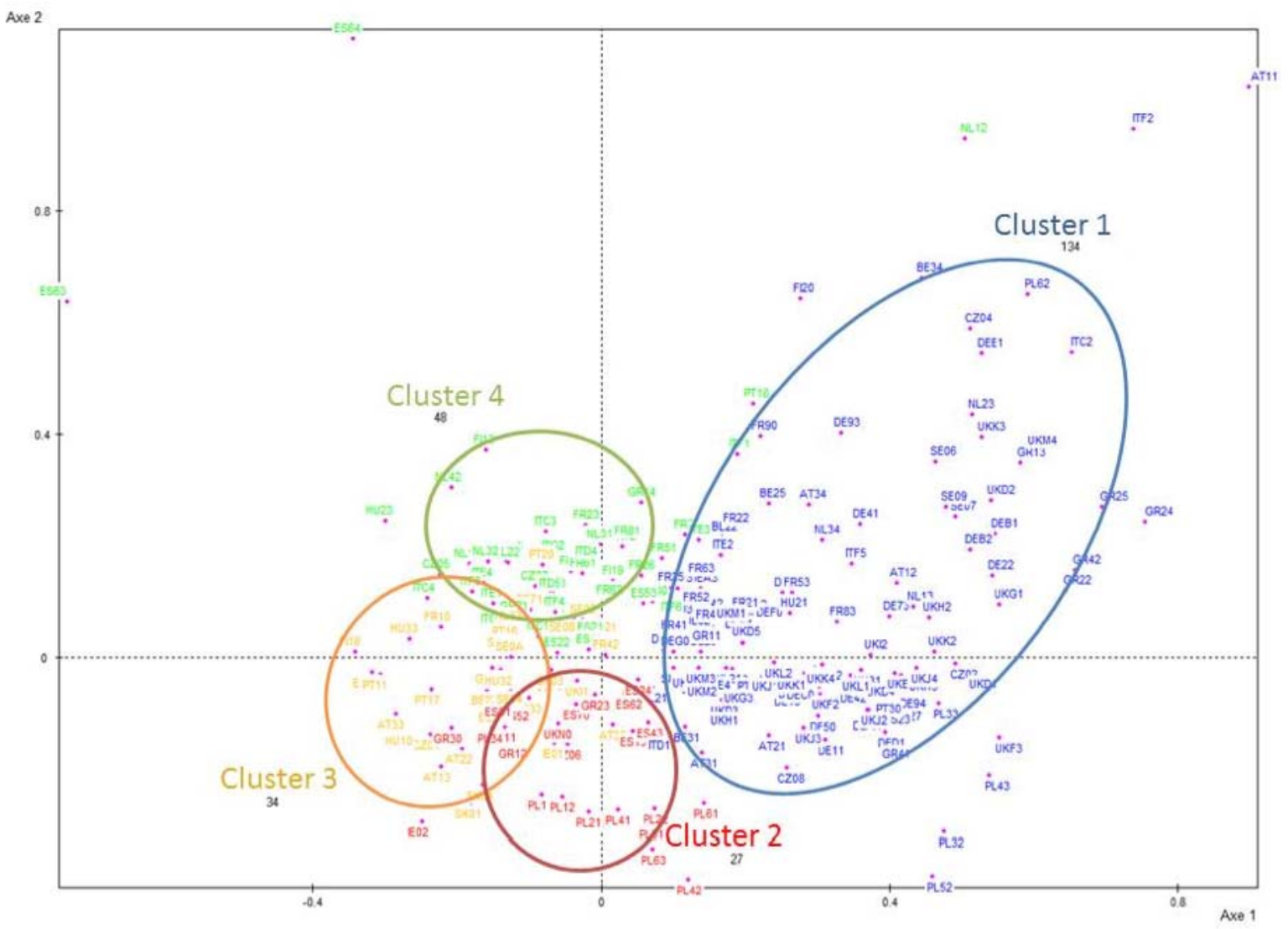

- Cluster 1 "National standard" gathers 134 European regions (about 55\% of the sample). The main characteristic of these regions is their higher propensity to collaborate within the same country and inside the same institution. The scientific networks tend to be restricted by national boundaries. Concerning the other aspects of connectivity (at European and international levels), these regions are situated in the average. They represent "standard" European regional behaviours of collaboration. The position of this cluster on the axes (Figure 2) shows a low connectivity between institutions of the same region and of the same institution.

- Cluster 2 “Autarkic" covers 27 regions (11\% of the sample) with a low scientific connectivity. The collaborations of regions, which are part of this cluster, are mostly intrainstitutional. Researchers are less likely to collaborate with scientists located in regions of the same country. This cluster appears in the negative part of the third axis (very low connectivity). 
- Cluster 3 "European network". These 34 regions (14\% of the sample) are characterized by the highest European collaborations and by co-authorship inside the same region (on the left part of the axes).

- Cluster 4 "Regional system" regroups 48 regions (20\% of the sample). These regions tend to collaborate inside the regional boundaries, and not much inside the same institutions (upper and left part on the factorial axes).

Clusters 4 and 3 are regionally oriented, but the main difference between those two types is the higher European co-publications rate in Cluster 3 (see Table 4).

Table 4 Scientific connectivity and average share of co-publications in 2009

\begin{tabular}{|l|c|c|c|c|c|c|}
\hline & $\begin{array}{c}\text { Intra- } \\
\text { institutional }\end{array}$ & Intra-regional & National & Eurapean & USA & $\begin{array}{c}\text { Other } \\
\text { international }\end{array}$ \\
\hline $\begin{array}{l}\text { I "National } \\
\text { Standard" }\end{array}$ & 45.26 & 12.81 & 23.57 & 9.35 & 2.88 & 6.23 \\
\hline 2 "Autarkic" & 51.57 & 24.82 & 8.79 & 8.81 & 2.23 & 3.77 \\
\hline $\begin{array}{l}3 \quad \text { "Eurapean } \\
\text { Network" }\end{array}$ & 37.85 & 27.22 & 9.62 & 15.26 & 3.75 & 6.30 \\
\hline $\begin{array}{l}4 \quad \text { "Regional } \\
\text { Systems" }\end{array}$ & 34.41 & 29.30 & 19.73 & 8.98 & 2.76 & 4.80 \\
\hline Full sample & 42.50 & 19.62 & 18.84 & 10.88 & 2.91 & 5.65 \\
\hline
\end{tabular}

Sources: Thomson Reuters and OST, computations of the authors

The four clusters of regions, reflecting types of scientific connectivity, reveal institutional and geographical specificities when projected on a map (Figure 3).

Figure 3. Typology of regional connectivity in Europe in 2009, computations of the authors 


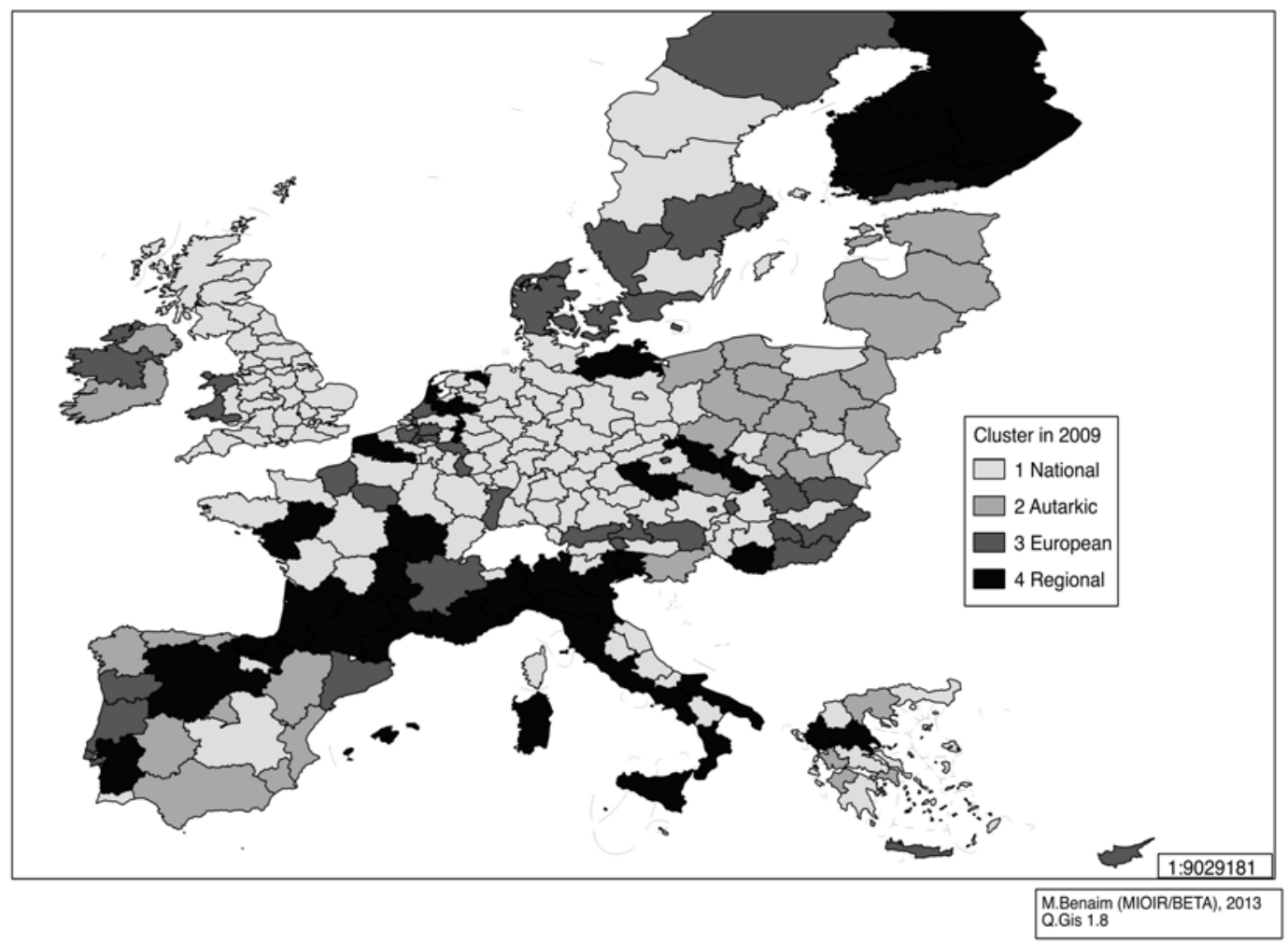

First of all, regions within the same country present - most of the time - the same characteristics of scientific activities. This result supports the idea that institutional and organisational rules as well as public policies tend to produce in the long run specific scientific behavioural routines. For example German and UK's regions (except MecklenburgVorpommern, London intra muros and Northern Ireland) are nationally oriented as far as scientific publications are concerned (Cluster 1 "National Standard"). Regions with a low connectivity (Cluster 2 "Autarkic") are to be found in Spain and Poland. Regional-oriented co-publications are strongly represented in Italy, Finland and to a lesser extent France. In the latter country, Alsace is one of the only regions being "European" with Ile-de-France and Rhône-Alpes (Cluster 3); Aquitaine (Cluster 4) seems to have successfully implemented its regional integration strategy and joined the group Midi-Pyrénées, Provence-Alpes-Côted'Azur and Languedoc-Roussillon (which by the way are high-ranking regions on innovation scoreboards). 
Amongst the regions composing the cluster 3 (European), two sub-groups could be distinguished. On the one hand the economic and political capital regions (Paris, Budapest, Helsinki, Lisbon, Vienna, Bratislava, Dublin or London, and one the other hand the regional hubs that have a more 'modest' size - inter alia - Rhône-Alpes, Cataluña, Alsace, Goteborg, Rotterdam, Porto, Liège, Malmö. For the regional capitals (and smaller-sized national capitals), the openness toward European partners might not be uniquely due to their size (as it is the case of large national capital cities with critical mass effects, intensive transportations networks, etc.). It could rather be due to i) cross border-regions' effects ${ }^{6}$ ii) an heritage: past dependency for regional hubs with an old scientific history and collaborations habits ${ }^{7}$; iii) a strategy of the scientific forces localized in the region to gain a stronger visibility; or iv) regional excellence centres that push the regional productions out of national borders. Despite obvious differences regarding the total amount of scientific productions at each level, these two sub-groups present close patterns of collaborations regarding their shares of extranational publications and thus compose a homogeneous group.

Twenty-seven regions are included in the cluster "autarkic regions". This group gathers regions isolated geographically at the periphery of Europe: there is probably distances effects (see HOECKMAN and FRENKEN, 2010). Some capitals like Madrid or Athens belong to this cluster. Despite the quite important scientific size of these regions in comparison with the other regions in this group, they appear as similar regarding their relative share of collaborations.

The typology of scientific connectivity highlights the diversity of regions presented in the literature as innovation leaders: Baden-Württemberg (Cluster 1 "National standard"), Catalonia (Cluster 3 "European networks") or Lombardy and Midi-Pyrénées (Cluster 4 "Regional System"). The so-called «blue banana», the innovation backbone of Europe, is more multi-coloured than expected from many typologies based on innovation statistics.

These clusters' characteristics have to be analysed in a more precise context. The following paragraphs present some economic and scientific characteristics for each cluster of our typology of scientific connectivity.

\footnotetext{
${ }^{6}$ The granularity of our data set does not allow us to differenciate the European co-publications from 'simple' cross-borders collaborations. For more details on cross-border collaboration See OECD (2013).

${ }^{7}$ In this respect we can note that old universities are localized in these regions: Univ. de Toulouse in MidiPyrenees (founded in 1229), Univ. de Louvain (1425), Univ. of Uppsala (1477), Univ. de Strasbourg (1538), or like Erasmus Universiteit Rotterdam who has by name a European openness.
} 
Each of the four clusters has specific characteristics regarding the size and the economic activities of the regions involved (see Table 5). The cluster 1 "National standard" includes smaller regions (measured by the population size and the GDP) but many of them have a relative high level of knowledge intensive activities (RHST/inhab.) Clusters 4 ("regional") and 3 ("European") include larger regions (in population and GDP). European cluster includes the more dynamic regions with high GDPs. It also includes many intensive knowledgeoriented regions. Apart of the capital regions, the cluster 2 concentrates a majority of autarkic regions economically isolated, with a low average GDP per capita.

Table - 5 Economic characteristics of the regions

\begin{tabular}{|ll|cccc|}
\cline { 3 - 6 } \multicolumn{1}{l|}{} & \multicolumn{4}{c|}{ Average in 2009 per cluster } \\
\hline Name & & HRST* $^{c \mid}$ & Inhabitants & GDP 2009** & RHST/inhab. 2009*** \\
\hline Cluster 1 & National & 334 & 1446038 & 34376 & 0.28 \\
Cluster 2 & Autarkic & 547 & 2758923 & 55303 & 0.19 \\
Cluster 3 & European & 525 & 2186134 & 66967 & 0.23 \\
Cluster 4 & Regional & 435 & 2344916 & 55966 & 0.19 \\
\hline \multicolumn{2}{|c|}{ Europe (243NUTS-2) } & 405 & 1873023 & 45526 & 0.25 \\
\hline
\end{tabular}

* Human Resources in Science and Technology (unit: in thousands)

** (SPA) in million €

*** Human Resources in Science and Technology per inhabitant

Sources: Eurostat, computation by the authors

The scientific size is measured by the total amount of publications in 2009 (see Table 6). The first observation is that the national oriented regions count a lowest volume of scientific production than the European average on the period. Indeed around $45 \%$ of those regions have less than 300 publications in 2009 and $90 \%$ of them do not reach more than 1500 scientific publications. Cluster 2 "Autarkic" is composed of $80 \%$ of « small regions » and « average size» regions (between 0 and 1500 publications in 2009). Thirty per cent of the regions in Cluster 4 "Regional system" count more than 1500 publications and six of them more than 2500 publications. One hypothesis can be drawn: those regions possess a dynamic RIS expressed by a high intensity of collaborations between institutions located inside regional scientific sub-system. Such regions have the necessary critical mass to develop structured research projects at the local level, but not all of them belong to cluster 4: the exceptions are Ile-de-France, London and Catalonia that are well endowed with scientific excellence institutions but are more oriented towards European or international networks (cluster 3). 
Table 6. Scientific size of the regions (measured by total amount of publications in 2009)

\begin{tabular}{|l|c|c|c|c|c|}
\hline & \multicolumn{4}{|c|}{ Number of scientific publications } & Number of \\
\cline { 1 - 4 } \% of each class & $0-300$ & $300-1500$ & $1500-2500$ & $\begin{array}{c}\text { More than } \\
2500\end{array}$ & $\begin{array}{l}\text { Numbions } \\
\text { Regions }\end{array}$ \\
\hline Cluster 1 National Standard & 44.03 & 45.52 & 5.22 & 5.22 & 134 \\
\hline Cluster 2 Autarkic & 10.00 & 70.00 & 6.67 & 13.33 & 30 \\
\hline Cluster 3 European & 16.22 & 40.54 & 18.92 & 24.32 & 37 \\
\hline Cluster 4 Regional & 16.67 & 54.17 & 16.67 & 12.50 & 48 \\
\hline
\end{tabular}

Sources: Thomson Reuters and OST, computations of the authors

The Correspondence Factorial Analysis performed here is based on the total amount of coauthored publications, but the scientific collaboration behaviours are not neutral to the scientific specialisations. Could specialisation explain the probability of a region to belong to a specific cluster? The data set considers eight disciplines in hard sciences. Table 7 below gives the scientific specialisations of the regions for each cluster.

Table 7 Specialisation Index by cluster

\begin{tabular}{|l|r|r|r|r|r|r|r}
\hline Specialization Index & \multicolumn{1}{|c|}{ Fdl Bio. } & $\begin{array}{c}\text { Med. } \\
\text { Research }\end{array}$ & Applied Bio. & Chemistry & \multicolumn{1}{c|}{ Physics } & \multicolumn{1}{c}{$\begin{array}{c}\text { Sc. of } \\
\text { Universe }\end{array}$} & Engineer \\
\hline $\begin{array}{l}\text { Cluster 1 National } \\
\text { standard }\end{array}$ & 0.80 & 0.90 & 1.37 & 0.98 & 0.89 & 1.21 & 1 \\
\hline Cluster 2 Autarkic & 0.77 & 0.76 & 1.37 & 1.32 & 0.97 & 1.08 & 1 \\
\hline $\begin{array}{l}\text { Cluster 3 European } \\
\text { Network }\end{array}$ & 1.06 & 0.93 & 1.26 & 0.99 & 0.87 & 1.09 & 1 \\
\hline Cluster 4 regional system & 1.05 & 1.13 & 1.23 & 0.89 & 0.79 & 0.98 & 0 \\
\hline
\end{tabular}

Sources: Thomson Reuters and OST, computations of the authors

The specialisation index is not significantly different following the clusters except for Applied Biology-Ecology. The " National Standard " model is close to the European average (not surprisingly since half of the sample is part of this cluster). The European oriented regions (cluster 3) are more specialised in Mathematics and under-specialised in Physics. The Autarkic regions (Cluster 2) are more focused on Chemistry, Engineering and Mathematics, rather than Medical research or Fundamental Biology. Cluster 4 ("Regional system") is mainly specialised in Medical research. Nevertheless these minor differences do not justify elaborating a model in which disciplinary specialisation explains scientific connectivity. 
The clusters are differentiated by their global scientific visibility (see Figure 4). The regions of Cluster 4 ("Regional system") appear as more visible and homogeneous as far as the citation index is concerned. This supports the idea that regional connectivity can be compatible with excellence. On the other side, Cluster 2 "Autarkic" is characterised by a low scientific visibility: high local connectivity is not a sign of excellence. The regions in Clusters 1 "National standard" and 3 "European network" are quite similar, as if competences inside a country could balance international networks.

Figure 4 Scientific visibility: Boxplot Impact Index in 2009 by cluster

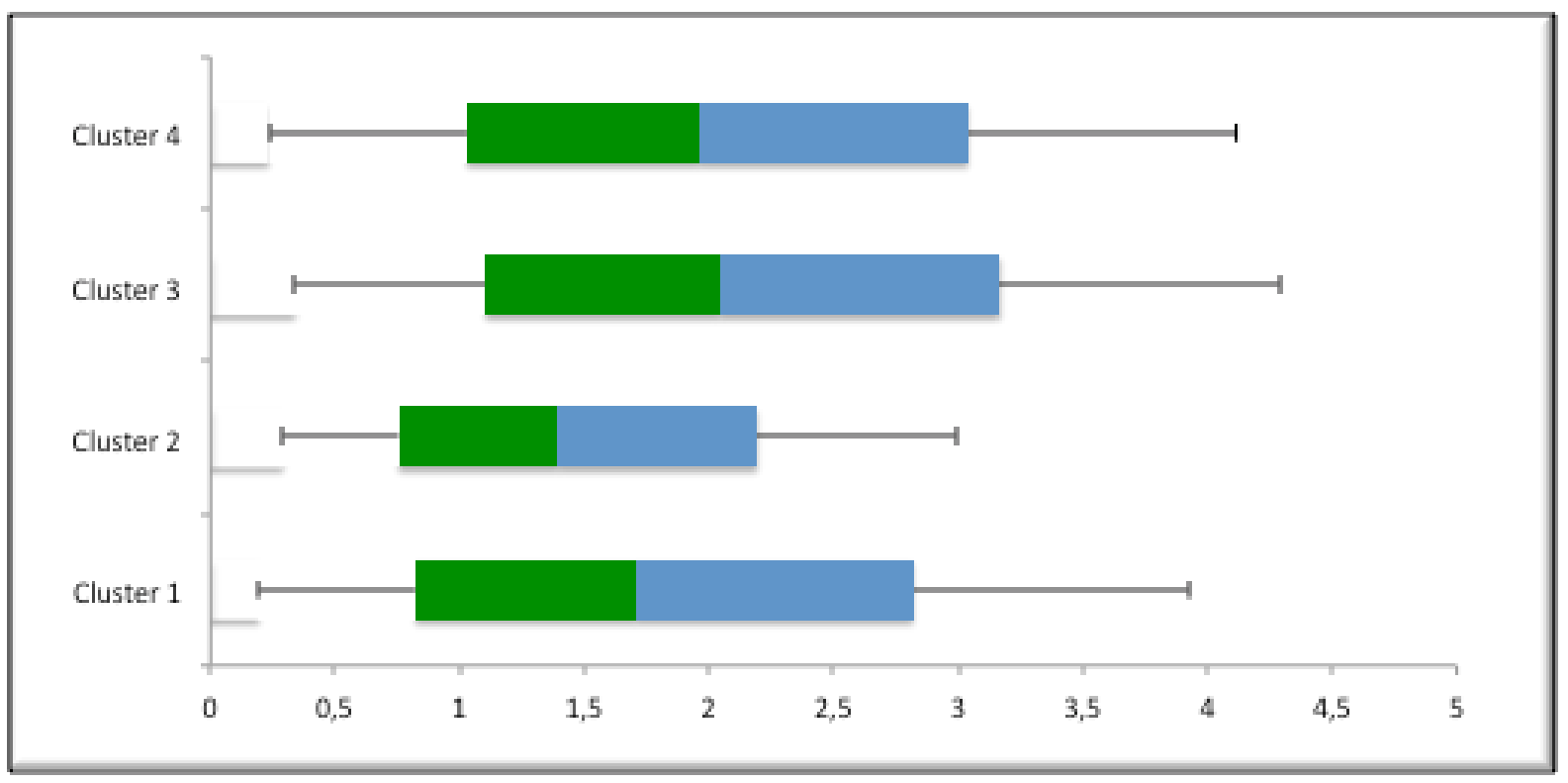

NB: Some impact indexes are not available for 15 regions, the latter were excluded from these boxplots. Sources: Thomson Reuters and OST, computations of the authors

\section{Discussion}

The regional typology based on scientific connectivity presented in this article, sheds new light on regional characteristics and on public policies.

\subsection{The scientific connectivity: a new map of European regions?}


The analysis of proximities based on scientific connectivity allows to go deeper into the characterization of the European regions. Results confirm regional R\&D characteristics underlined by previous studies, but justify a complementary approach between scientific connectivity and the traditional RIS characteristics. It is interesting to quote that the regions that are more "European-oriented" in the typology of scientific connectivity are also the richer and the more knowledge-intensive. At the opposite, the "autarkic" group is mostly composed of peripheral regions (in geographic and economic terms).

Furthermore the typology of scientific connectivity brings new regional characteristics in terms of R\&D. The typologies of European regions constructed through R\&D and innovation indicators (KROLL et al., 2009; PINTO, 2009; OECD 2011) are slightly different from the typology elaborated on indicators of scientific connectivity. For example, the typology proposed by OECD (2011) on regional innovation capabilities identifies knowledge intensive regions and scientific/technological hubs (variety of sectors and S\&T competences, R\&D intensity in High Tech. and Science). These "hubs" (Ile-de-France, Midi-Pyrénées, London intra muros, Berlin, Bremen and Hamburg) are classified in a different way according to the typology of scientific connectivity.

The national versus regional dimension of scientific connectivity is the first opposition resulting from the statistical analysis. This result fits with many studies conducted on the link between scientific networks and geographical proximities (FRENKEN et al., 2009). The national boundaries are probably the main obstacle to scientific networks, not for proximity reasons but for institutional reasons. Conversely, regions in smaller countries where researchers succeed to co-operate internationally are generally in a better position. This is clearly an important issue for science policies.

The originality of this typology and the new European map it draws is not the result of the differences in scientific specialisations between regions. Other dimensions arise. For instance, belonging to a strong national system appears to explain statistically the collaboration schemes. The European research area apparently has a degree of relevance which is quite variable among regions, following the critical mass of their national environment.

Some characteristics of scientific connectivity appear at first as surprising for some regions. The UK's regions are characterised by their propensity to collaborate within the national boundaries whereas HOECKMAN et al. (2010) or other studies underline the international network(ed) orientation of these regions. This opposition is not so conflicting, if we go deeper 
into the characteristics of Cluster 1 "National Standard". The regions of this cluster have a share of national collaboration higher than the average of other regions in Europe, but it does not mean that these regions have no European or international collaborations: Cluster 1 "National standard" deals with regions that are in the European average for European collaboration and a bit higher for collaborations with the USA. This typology supports the need for a variety of indicators of scientific connectivity depending on geographical collaboration areas.

\subsection{Scientific connectivity and regional policy implications}

The local versus global connectivity in the RIS is an issue for public policies at the local level (BENNEWORTH, 2010). It represents today a great challenge for the implementation of the innovation programs covered by Horizon 2020 (EUROPEAN COMMISSION, 2010). How to take advantage of the diversity of those connections?

In the context of distributed knowledge and of new forms of open innovation, the relations between actors and their environment have changed (TEIRLINK et al., 2008; BATHEILT et al., 2004; MALECKI, 2010). As far as scientific activities are concerned there is no radical transformation, because open-science governance is well known in the literature. The increasing role of open-innovation and open-science mechanisms on the one hand, and the power transferred by the European Union to local/regional authorities for R\&D policies, on the other hand, are modifying the way policy makers should tackle these activities in order to sustain territorial development. Enhancing scientific networks becomes a relevant policy target at the regional level. Linking organisations such as brokerages, places for industryscience interactions, common infrastructures and platforms, are implemented in order to reinforce existing relationships or to create new connections that foster creative processes.

The case of French regions is interesting for illustrating the trend towards more scientific collaboration inside and outside the regional boundaries, using various policy instruments. Some French regions (mainly Aquitaine, Rhône-Alpes, Loraine and Basse-Normandie) implement explicitly structured public policies on this issue. The policy instruments are defined in a generic policy strategy document, with budgets or financial incentives given to the regional actors of the RIS. 
- Regions encourage actions in favour of international mobility of researchers: exchange programs and incentives to mobility of young researchers, financing international university "chairs" to attract star scientists into the region.

- Regions give financial support for inter-regional collaborative projects focused on specific thematic areas.

- Regions support the accessibility of local scientific infrastructures to foreign researchers.

- Regions encourage new links by financing international events or animating regional clubs (on topics considered as strategic for the region).

The diversity of scientific connectivity schemes presented in this article leads to highlighting the need for differentiated instruments supporting local-global collaborations. The policies must be designed according to the territorial characteristics: concentration of financial supports, industrial-technological-scientific specialisations and complementary resources of the RIS actors (NUUR et al., 2009; MALECKI, 2010). Three issues are raised by the results of the above typological study:

First, what could be a good strategy for a small scientific region to reach a sufficient scientific critical mass? There are two options. The first one deals with the small regions located in large countries. These regions take advantage of national collaborations because of the geographical, institutional and cultural proximity. Promoting national scientific collaborations might be a modality to increase the local scientific capacity. The option could be more costeffective (in terms of coordination costs) than policies aiming at international collaborations. A second option deals with small regions located in small scientific country. These regions, by collaborating worldwide or at least within Europe have access to valuable additional resources.

Second, how could regional policymakers support scientific reputation through enhanced connectivity? This approach suggests that specific forms of scientific connectivity (localglobal interactions) might be a source of competitive advantage (KRATKE et al., 2009) like the regions in Cluster 4 "Regional system": these regions exhibit strong local scientific collaborations and, at the same time, are active in international and European collaborations. Big scientific regions (measured by the number of publications) seem to be more suited to develop this kind of strategy of connectivity. 
Third, on the opposite side, the autarkic regions (with small or intermediate scientific sizes) are less visible in the scientific area. The hypothesis here relates to the difficulty for these regions to build a critical mass based on local collaborations, especially if there is no real integrated RIS and no collective strategy (ANOVA et al., 2001). The citation index becomes at the same time an indicator of visibility (and of quality) of the research, and a proxy to evaluate the ability of the scientists to join international networks (MEYER, 2008). In the case of Cluster 2 "Autarkic", the role of regional policymakers could focus on the reinforcement of the local scientific absorptive capacities by promoting selective international partnerships. Academics in Autarkic regions need some support for (at least) better understanding the global rules of the scientific game.

\section{CONCLUSION}

The connectivity approach of regional science based on co-publications statistics revives the RIS's issue. This study focused on the scientific background of the knowledge economics and produced new regional maps of Europe - relatively different from the classical ones expressing the R\&D point of view. This study aimed at adding new indicators in the perspective of a richer innovation analysis (scientific creation depends on connectivity factors as well as on research intensity measured in R\&D expenditure). It also suggested new possibilities to think regional public policies in a global-local perspective.

There are still some limitations in this study, that requires to go deeper into the analysis of regional connectivity. To start with, an econometric analysis could be implemented in order to better evaluate the determinants of the various forms of scientific connectivity. Then, a similar analysis on technology (for instance using co-invention statistics) would bring a broader view on the innovation landscape: such indicators make it possible to identify technological connectivity at the level of regional system, and for activities that are closer to market perspectives than scientific activities.

\section{REFERENCES}

Adams J.D., Grant G.C., Clemmons J.R. and Stephan P.E. (2005), Scientific teams and Institutional collaborations: evidence from US Universities, 1981-1999, Research Policy, 34 (3), 259285. 
AMIN A. and COHENDET P. (2004), Architectures of knowledge. Firms, capabilities, and communities, Oxford University Press, Oxford.

ANOVA R.W. and LEYDERSDORFF L. (2001) Why Catalonia cannot be considered as a regional innovation system, Scientometrics 58 (2), 215-240.

ASHEIM B.T. (ed.) (2006) Constructing regional advantage: principles, perspectives, policies, European Commission Report, Brussels.

ASHEIN B.T. and COENEN L. (2005) Knowledge bases and Regional innovation systems: comparing Nordic clusters, Research Policy, 34, 1173-1190.

BAIER, E. (2011) Multinational enterprises in regional innovation systems: attraction factors and integation mechanisms. Phd Dissertation, Université de Strasbourg et KIT (Karlsruhe).

BALDINI N. (2010) University spin-offs and their environment, Technology analysis and Strategic management 22 (8), 859-876.

Bathelt H., Maimberg A. and MAskell P. (2004) Clusters and Knowledge: local buzz, global pipelines and the process of knowledge creation. Human Geography 28 (1), 31-56.

BEAUDRY C. and BRESCHI S. (2000) Does clustering really help firms' innovative activities. CESPRI working paper $\mathrm{n}^{\circ} 111$, University of Bocconi.

BEAVER D. (2001) Reflections on scientific collaboration, Scientometrics, 52, 365-377.

BENNEWORTH P. (2010) Globalisation and regional studies for the 21st Century: beyond global pipelines, local buzz. Conference of the Nordic Regional Studies Association,

BENNEWORTH P. and DASSEN A. (2011) Strengthening Global-Local Connectivity in regional innovation strategies. OECD Regional Development working paper 2011/01, OECD, Paris.

BENNEWORTH P. and HOSPERS G.J. (2007) The new economic geography of old industrial regions: universities as global/local pipelines, Environment and Planning: Government and Policy 25 (6) 779802

BenNeworth P., Coenen L, MoOdysson J. and Asheim B. (2009) Exploring the multiple roles of Lund university in strengthening scania's regional innovation system: towards institutional learning ?, European Planning Studies 17 (11), 1645-1664.

BRUIJN P.J. and LAGENDIJK A. (2005) Regional innovation systems in the Lisbon Strategy, European Planning Studies 13(8), 1153-1172

CATTELL R.B. (1966) The scree test for the number of factors. Multivariate Behavioral Research, 1, 629-637.

CohEN W. M. and Levinthal D. (1990) Absorptive capacity: A new perspective on learning and innovation, Administration Science Quarterly, 35, 128-152.

COHENDET, P., GRANDADAM, D. and SiMON, L. (2010) The anatomy of the creative city, Industry and Innovation, 17, 91-111. 
CONSEIL REgIONAL DE RHONE-AlPES (2010) Diagnostic en vue du schéma régional de l'enseignement supérieur et de la recherche de Rhône-Alpes, Document interne.

COOKE P. (2001) Regional innovation systems, clusters, and the knowledge economy, Industrial and Corporate Change 10 (4), 945-974.

COOKE P. (2004) Les régions comme laboratoires de développement axés sur la connaissance : qu'est ce qui a changé depuis 1995 ?, Géographie, Economie, Société, 153-161.

COOKE P. (2005) Regionally asymmetric knowledge capabilities and open innovation: exploring 'Globalisation 2'” - A new model of industry organization, Research Policy 34, 1128-1149.

Crespy C., Héraud J. A. and Perry B. (2007) Multi-level governance, regions and science in France: between competition and equality, Regional Studies, 41(8), 1069-1084.

DELAPLACE M. (2009) L'orientation locale des politiques scientifiques: entre coopérations et enfermement une illustration en Champagne-Ardenne, Revue d'économie régionale \& Urbaine, 53-74

DOLOREuX D. and BITARD P. (2005) Les systèmes régionaux d'innovation: discussion critique, Géographie, Economie et Société 7, 21-36

DORE J.C., OJASOO T., OKUBO Y., DURAND T., DUDOGNON G., and MIGUEL, J. F. (1996) Correspondence factor analysis of the publication patterns of 48 countries over the period 19811992, Journal of American society for information science 47 (8), 588-602.

ETZKOWITZ H. and LEYDESDORFF L. (eds) (1997) Universities in the Global Economy: A Triple Helix of University-Industry-Government Relations. London: Cassell Academic.

EUROPEAN COMMISSION (2010) La contribution de la politique régionale à une croissante intelligente dans le cadre de la stratégie "Europe 2020", Communication de la commission européenne COM (2010) 553 final

FRENKEN K., HARDEMAN S. and HoEKMAN J. (2009) Spatial scientometrics: towards a cumulative research program, Journal of infometrics 3, 222-232

GEORGHIOU L. (1998) Global cooperation in research.,Research Policy 27, 611-626

GLANZEL W. (2001) National characteristics in international scientific co-authorship relations, Scientometrics 51 (1), 69-115

HÉRAUD J.A (2011) Reinventing creativity in old Europe: a development scenario for cities within the Upper Rhine Valley cross-border area, City, Culture and Society 2, 65-73.

HÉRAUD J.A (2003) Regional innovation systems and European research policy: Convergence or misunderstanding?., European Planning Studies, 11 (1), 41-56

HoElman J., FrenKen K. and TiJSSEN R.J. (2010) Research collaboration at a distance: changing spatial patterns of scientific collaboration within Europe, Research Policy 39, 662-673.

KAISER H.F. (1960) The application of electronic computers to factor analysis. Educational and Psychological Measurement, 20, 141-151. 
KLINE, S.J. and N. Rosenberg (1986) An overview of innovation, in R. Landau \& N. Rosenberg (eds), The Positive Sum Strategy: Harnessing Technology for Economic Growth. Washington, D.C.: National Academy Press, 275-305.

KRATKE S. and BRANDT A. (2009) Knowledge Networks as a Regional Development Resource: A network Analysis of the interlinks between scientific institutions and regional firms in the Metropolitan region of Hannover, Germany,European planning studies 17 (1), 43-63.

LA RECHERCHE (2011) L'Aquitaine. Terre d'excellence scientifique, Supplément à La Recherche, 456, octobre.

LEYDESDORFF L. (2000) Is the European Union becoming a single publication system?, Scientometrics 47 (2), 265-280

LEYDESDORFF L. (2003) The mutual information of university-industry-government relations: An indicator of the Triple Helix dynamics. Scientometrics, 58 (2), 445-467.

LeYdesdorfF L. H. and EtzKowitz E. (1998) The Triple Helix as a model for innovation studies. Science and Public Policy, 25, 195.203.

LundVAll B.A., Johnson B., ANDERSEN E.S. and DAlum B. (2002) National systems of production, innovation and competence building. Research policy, 31 (2), 213-231.

LUUKKonen T., PEARsSON O. and SiVERTTSEN G. (1992) Understanding patterns of international scientific collaboration. Science, Technology \& Human values, 17 (1), 101- 126.

LuUkkonen T., TJissen R.J.W., Pearsson O. and Siverttsen G. (1993) The measurement of international scientific collaboration. Scientometrics 28, 15-36.

MALECKI E.J. (2010) Global knowledge and creativity: new challenges for firms and regions. Regional studies 44 (8), 1033-1052.

MALECKI E. and OINAS P. (1999) Making connections: Technological leraning and regional economic change. Aldershot: Ashgate.

MARKUSEN A. (1994) Studying regions by studying firms. The professional geographer, 46 (4), 477 490.

MATTES J. (2006) Innovation in multinational companies - an empirical analysis of innovation networks between globalization and localization. Bamberger Beiträge zur Europaforschung und zur internationalen Politik Nr 14/2006, Bamberg, Germany, University of Bamberg.

Mattson P., Lget P. Nilsson A. and Sundberg C.J. (2008) Intra-EU vs extra-EU scientific copublication patterns in EU. Scientometrics 73 (3), 555-574.

MORENO R. and MIGUÉLEZ E. (2012) A relational approach to the geography of innovation: A typology of regions. Journal of Economic Surveys 26(3), $492-516$

NAVARRO M. and GIBAJA J.J. (2009) Typologies of Innovation based on statistical analysis for European and spannish regions, Innova Working paper 2009.

NIOSI J. and ZHEGU M. (2005) Aerospace clusters: local or global knowledge spillovers? Industry and Innovation 166 (1), 123-139. 
NuUR C., Gustavsson L. and Laestadius S. (2009) Promoting regional innovation systems in a global context. Industry and Innovation 16 (1), 123-139.

OECD (2013), Regions and Innovation: Collaborating across Borders, OECD Reviews of Regional Innovation, OECD Publishing.

OCDE (2011) Regions and innovation policy. OECD Review of Regional Policies, OECD Publishing.

OST ‘(2009) Rapport des indicateurs de sciences et techniques, La Documentation française, Paris

OкUBO Y. and ZiTT M. (2004) Searching for research integration across Europe: a closer look at international and iner-regional collaboration. Science and Public Policy, 31, 213-226.

OUghton C., LANDABASO M. and MORGAN K. (2002) The regional innovation paradox: innovation policy and industrial policy. Journal of Technology Transfer 27. 97-110.

Persson O., Glanzel W. and Danell R. (2004) Inflationary bibliometric values: the role of scientific collaboration and the need for relative indicators in evaluate studies. Scientometrics 30 (3), 421-432.

PINTO H. (2009) The diversity of innovation in the European Union: Mapping latent dimensions and regional profiles. European planning studies 17 (2), 303-326.

TEIRLINCK P. and SPITHOVEN A. (2008) The spatial organization of innovation: open innovation, external knowledge relations and Urban structure. Regional Studies 42 (5), 689-704.

Thus B. and GLANZEL W. (2008) A structural analysis of publication profiles for the classification of European research institutes. Scientometrics 74 (2), 223-236.

TIJSSEN R.W. and VAN LEEUWEN T.N. (2007) Research cooperation within Europe: bibliometric views of geographical trends and integration processes. in Torres-Salinas, D. Moed H. (eds), Proceeding trends and integration, proceedings of the ISSI 2007, CINDOC CSIC Madrid, -744

TODTLING F. and TRIPPL M. (2005) One size fits all? Towards a differentiated regional innovation policy approach. Research Policy 34, 1203-1219.

TORRE A. (2008) On the role played by temporary geographical proximity in knowledge transmission. Regional Studies 42 (6), 869-889.

UYARRA E. (2010) What is evolutionary about 'regional systems of innovations, implications for regional policy. Journal of evolutionary economy 20, 115-137.

UYARRA E. and FLANAGAN, K. "Reframing regional innovation systems: Evolution, complexity and public policy." In Reframing Regional Development, ed. Cooke, P, Routledge, 2013.

WAGNER C. (2005) Six case studies of international collaboration in science. Scientometrics 62 (1), 326.

WAGNER C.S. and LEYDESDORFF L. (2005) Network structure, self-organization, and the growth of international collaboration in science. Research Policy 34, 1608-1618. 
WAGNER C.S., BRAHMAKULAM, JACKSON B., WONG A. and YodA T. (2001) Science and technology collaboration: building capacity in developing countries. Rand Europe, Science and Technology, Santa Moncia

WARD J.H. (1963) Hierarchical grouping to optimize an objective function, Journal of the American Statistical Association (58), 236-244.

ZitT M., BASSECOUlaRd E. and OKUBO Y. (2000) Shadows of the past in international cooperation: collaboration profiles of the top five producers of science. Scientometrics, 47 (3), 627-657.

ZuCKeR L.G., DARBY M.R. and ARMSTRONG J.S. (1998) Geographically localized knowledge: spillovers or markets?, Economic Inquiry 36, 65-86. 
APPENDIX A: Hierarchical classification and clustering.

As PINTO 2009; BALDINI 2010; NAVARRO and GIBAJA, 2009, and other typology's exercise in RIS's studies we used a hierarchical cluster analysis to construct well-balanced clusters. The cluster membership is determined by computing the variance of the elements: the sum of the squared deviations from the mean of the cluster also known as the Ward's method (Ward, 1963). A region will belong to a cluster if it produces the smallest possible increase in the variance. Our 243 Nuts-2 were distributed in four clusters (see the dendrogram on Fig. A.1).

Table A.1: Matrix of the distances between clusters.

\begin{tabular}{|l|c|c|c|c|}
\hline & Cluster 1/ 4 & Cluster 2/ 4 & Cluster 3/ 4 & Cluster 4/ 4 \\
\hline Cluster 1 / 4 & 0,0000 & 0,3418 & 0,3937 & 0,3489 \\
\hline Cluster 2 / 4 & 0,3418 & 0,0000 & 0,2533 & 0,2840 \\
\hline Cluster 3 / 4 & 0,3937 & 0,2533 & 0,0000 & 0,2215 \\
\hline Cluster 4 / 4 & 0,3489 & 0,2840 & 0,2215 & 0,0000 \\
\hline
\end{tabular}

Figure A.1: Cluster analysis dendrogram

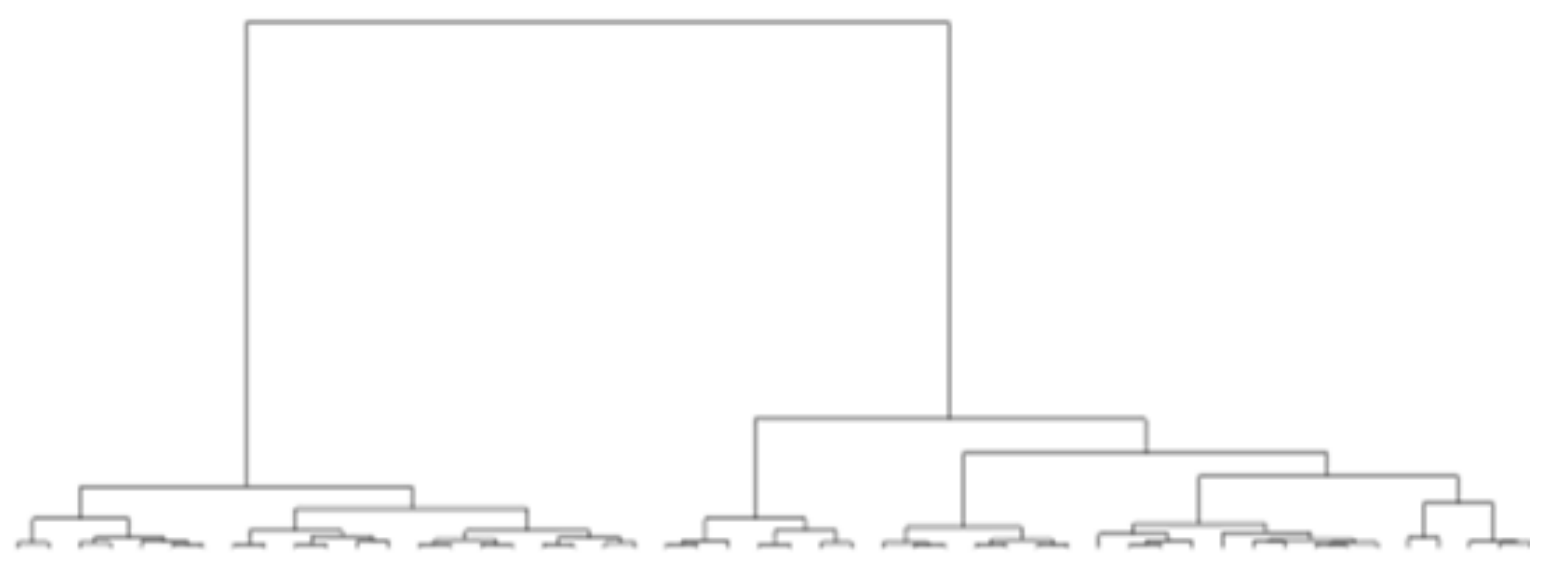

